\title{
Spelling Scoring Metrics in Malay Language: An Investigation among Young Spellers
}

\author{
Swee Gek Tang \\ Faculty of Cognitive Sciences and Human Development, Universiti Malaysia Sarawak, 94300 Kota Samarahan, \\ Sarawak, Malaysia \\ Julia Ai Cheng Lee \\ Faculty of Cognitive Sciences and Human Development, Universiti Malaysia Sarawak, 94300 Kota Samarahan, \\ Sarawak, Malaysia \\ Jecky Misieng \\ Faculty of Language and Communication, University Malaysia Sarawak, 94300 Kota Samarahan, Sarawak, Malaysia
}

\begin{abstract}
The aim of this study was to investigate the relationship among three spelling scoring metrics, namely, words spelled correctly (WSC), correct letter sequences (CLS), and phonological coding (PC) in Malay language. The relationship between spelling measure and word reading measure was studied. There were 866 Primary 1 (Grade 1 equivalent) students from 11 randomly selected public primary schools in Kuching, Sarawak Malaysia who participated in this study. The study showed that the scores from each scoring metric were highly correlated to each other. There was a strong relationship between each spelling outcome to word reading.
\end{abstract}

Index Terms — scoring metrics, spelling, reading, Malay language

\section{INTRODUCTION}

Literacy skills are clearly more than just reading. It involves both reading and writing. Spelling is an essential part in both reading and writing. It helps improve learner's reading, writing fluency, and vocabulary (McCardle, Chhabra, \& Kapinus, 2008). However, reading is always treated to be more important than spelling at schools (Treiman, 1998). According to Snow, Griffin, and Burns (2005, p.86) "spelling and reading build and rely on the same mental representation of a word. Knowing the spelling of a word makes the representation of it sturdy and accessible for fluent reading". Besides, spelling is a foundation for helping students master the basic language, especially those students who may struggle with reading (Jones, 2009). Therefore, spelling must still be specially taught and learned in schools.

\section{A. The Malay Language}

Malay (Bahasa Malaysia) is the official language of four South East Asia countries, namely Brunei, Indonesia, Malaysia, and Singapore. It is also the first language of majority of the 27 million people in Malaysia (Department of Statistics Malaysia, 2011).

The Malay alphabet has the same 26 roman alphabet letters like English, which is, the letters from $\langle a\rangle$ to $\langle z\rangle$. There are three types of sounds in the Malay writing system, which are consonants, vowels, and diphthongs (Awang, 2004). In addition, there are 21 consonants and the correspondence between the consonant letters and consonant sounds of the Malay language is almost perfectly one to one (Awang, 2004; Lee, Liow, \& Wee, 1998; Lee, 2008). There are five pure vowels $(\mathrm{a}, \mathrm{e}, \mathrm{i}, \mathrm{o}, \mathrm{u})$ with six vowel sounds. Nevertheless, there is an exception for the letter ' $\mathrm{e}$ '. It has carries two vowel sounds, overlapping in the grapheme-phoneme coding of vowel letters and vowel sounds, such as /e/ as in enak (delicious) and /ə/ as in emas (gold) whereas other graphemes carry only one unique sound. There are three diphthongs in the Malay language written as 'ai', 'au' and 'oi' which carry a single phoneme (/ai/, /au/ and /oi/). There are five digraphs written as 'gh', 'kh', 'ng', 'ny' and 'sy' that also correspond to one phoneme each (/gh/, /kh/, /ng/, /ny/ and /sy/) (Awang, 2004). The Malay language is based on phonemic units but the syllable is a salient unit because Malay words have distinct syllable structures (Isahak, 1990). Syllable is a phonological unit formed by a vowel, diphthongs or with or without surrounding consonants. The native Malay words are typically based on four types of syllable: V, VC, CV and CVC (Gomez \& Reason, 2002; Hamdan, 1988). The phonological structure of Malay words can be described in terms of both syllable and phonic structures. Words can range from very simple syllable structures CVCV (i.e. susu which means milk) to more complex syllable structures like CVCCVVCV (i.e. sentiasa which means always). The Malay language is consistent and transparent language as the grapheme-phoneme correspondences is almost perfect one-to-one relationship (Awang, 2004).

B. Spelling and Reading 